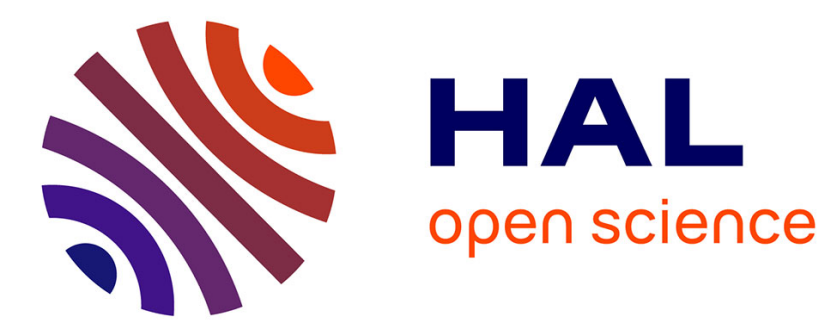

\title{
A linguistic framework for knowledge, belief, and veridicality judgement
}

Anastasia Giannakidou, Alda Mari

\section{To cite this version:}

Anastasia Giannakidou, Alda Mari. A linguistic framework for knowledge, belief, and veridicality judgement. Know, 2021, 5 (2), 10.1086/716348 . halshs-03088697

\section{HAL Id: halshs-03088697 https://shs.hal.science/halshs-03088697}

Submitted on 26 Dec 2020

HAL is a multi-disciplinary open access archive for the deposit and dissemination of scientific research documents, whether they are published or not. The documents may come from teaching and research institutions in France or abroad, or from public or private research centers.
L'archive ouverte pluridisciplinaire HAL, est destinée au dépôt et à la diffusion de documents scientifiques de niveau recherche, publiés ou non, émanant des établissements d'enseignement et de recherche français ou étrangers, des laboratoires publics ou privés. 


\title{
A linguistic framework for knowledge, belief, and veridicality judgement
}

\author{
Anastasia Giannakidou and Alda Mari \\ University of Chicago and Institut Jean Nicod CNRS/ENS/EHESS/PSL
}

December 26, 2020

\section{The core questions}

The relation between language and thought has been central in many disciplines including philosophy, linguistics, psychology, anthropology, to mention just some. For the Ancient Greek thinkers, logos refers to both thought (specifically, ability of humans to think logically) and language, therefore a symmetry is projected in the relation of the two: the ability to think needs language to express thought. Moreover, for thinkers like Aristotle this relation is universal: thoughts do not vary according to language, but language is the universal vehicle for representing thought. For Plato, likewise, as lucidly expressed in Cratylus, objects have their essence (ousia) and the task of name-givers is to discover the essence and name accordingly. The Greek view is descriptive and representational: the thought and the world exist independent of language, and language serves to describe it. Language does not by itself create a reality, although in rhetoric and in sophistry the truth of sentences can be manipulated to exploit gaps in logic that can lead to flawed conclusions.

In contrast to this descriptive view, the so-called Sapir-Whorf hypothesis stipulates a primacy of language over thought such that thought is determined by the language. This position- widely popular in (mostly non-linguistic) circles, and epitomized in Wittgenstein's famous saying The limits of my language means the limits of my world - is one of relativism and language supremacy: in its strongest form, the position says that the language spoken by a community (a) fully determines the thought frame within which the community understands the world, and therefore (b) places limitations on how linguistic agents perceive and construct the world. The linguistic supremacy position views language as a world creating and restricting device, in contrast to the Greek view where the function of language is merely to represent and describe the world.

In this paper, we will approach the question of language, thought and reality by studying how grammar and the lexicon encode our relation to the world. We will address the fundamental categories of knowledge and belief, and focus on specific grammatical devices such as mood morphemes (subjunctive and indicative), attitude verbs of knowledge and belief, and expressions of possibility and necessity such as modal verbs (must, may, will, might). What is the function of these expressions? How much do they tell us about the nature of knowing and believing? Is a language like English, which lacks subjunctive and indicative, missing something crucial compared to languages such as Greek and Italian which have productive mood morphology? Is the absence of mood a deficiency for knowledge or belief?

We will argue that the function of modal and propositional attitude verbs is to be truth manipulators: they express whether speakers are fully or partially committed to the truth of a proposition, and whether they do so based on objective (i.e. truth), or subjective criteria. In believing, commitment relies on subjectively veridical constructs of truth that commit speakers solipsistically, and 
sometimes in defiance of actual truth, as is the case, for example, with predicates of dream and imagination that select the indicative - the mood otherwise indicating knowledge.

Knowledge verbs form the only realm that engages truth and the world directly, and whose complement sentences can refer to actual facts. In any other embedding, the world and reality are accessed only privately and indirectly, via subjective representations that individuals constructwhich we will call " "information states", "modal bases", and more broadly the body of evidence. When a choice is made to use a modal expression or a propositional attitude verb, the speaker (as is the case with modals) or the propositional attitude bearer (as is the case with attitude verbs) is expressing a stance toward truth by admitting essentially that she lacks knowledge. These stances form veridicality commitments that can be stronger or weaker, depending on the modal or the chosen attitude. Language, therefore, functions both descriptively - in articulating the full commitment of knowledge-and subjectively via solipsistic veridical constructs; and some predicates, i.e., the Italian belief verbs that we will describe as 'suppositional beliefs' later, contain both components. This paper therefore ultimately serves as an argument for the need for careful linguistic analysis in trying to answer the question of language and thought.

The discussion proceeds as follows. We outline the core distinction between veridical and nonveridical stance based on our recent work (Giannakidou and Mari 2016, 2018a,b, 2021) in section 2, where we develop a theoretical framework focussing on the English modal verbs which we analyze as 'anti-knowledge' markers. We then talk about the body of evidence as determining the veridicality judgement in section 3 , where we also note that it is to be distinguished from what we call 'emotive' content which is subjective and therefore less reliable (see Giannakidou and Mari 2016b). We move on to question of mood choice and propositional attitudes in section 4, where we illustrate the basic paradigms of knowledge and belief in Greek and Italian. We establish two kinds of belief in sections 5 and 6, the one that we called solipsistic and which is purely subjective, and another one which is suppositional (as we call it in Giannakidou and Mari 2021) and conjectural, and contrasts belief with knowledge. We elaborate on the nature of evidence, endogenous or exogenous in section 7 and make some additional observations about the direction of fit. We conclude in section 8 that Greek, Italian, and English do not differ fundamentally just because the latter lacks productive mood marking in complement clauses. In English, the effect of mood morphemes is taken up by modal verbs or tense, and the linguistic system has the same expressive power.

\section{Veridical and nonveridical stance}

Consider the following declarative sentences. One contains a simple past tense, another one has the present tense, two sentences contain the modal verbs (must and may), and one contains the future modal will:
a. It is raining.
b. It rained.
c. It must be raining.
d. It may be raining.
e. It will rain.

Let us call the tensed sentences without modal verbs "bare". In linguistic semantics and pragmatics we assume that the assertion of a bare sentence requires that the speaker follows the Gricean principle of Quality (Grice 1957), which is a fundamental principle for co-operative conversation. Quality demands that the speaker be truthful, and this means that when uttering a bare sentence, 
she knows, or has grounds to believe that it is raining or that it rained. ${ }^{1}$ By uttering the sentence "It is raining", the speaker wants to share her knowledge or belief with her audience. Information flow, in other words, and sharing information more broadly means that the speaker intends the proposition denoted by the bare sentence to be added to the 'common ground' of the conversation. Upon adding the proposition to the common ground, a listener might object if they know or believe otherwise, e.g., if they just came back from outside and it is no longer raining. But insofar as the speaker is concerned, and given what she knows or believes at the time of utterance, it is true that it is raining or that it rained.

When the speaker has this knowledge, we say that the speaker takes a veridical stance towards the proposition It is raining (Giannakidou and Mari 2018a,b, 2021; Giannakidou 1998, 2013). We can think of the veridical stance as the mental state (or, attitude) of commitment to truth. This is not commitment in the sense of commitment to act; veridical commitment is independent of action since it relies purely on knowledge and belief. The veridical stance is commitment to truth motivated by information that the speaker possesses that we will call the body of evidence.

In Giannakidou and Mari 2021 we establish veridical commitment as the prerequisite for assertion:

Veridical commitment as a prerequisite for assertion:

A sentence $S$ is assertable if and only if the speaker is veridically committed to the proposition $p$ denoted by $S$.

Commitment is a kind of certainty of the speaker, who acts as the the linguistic anchor or agent. The linguistic anchor is not always the speaker. As we shall see, when we have propositional attitude verbs such as in Ariadne believes that it is raining it is Ariadne's not the speaker's certainty that take center stage. The speaker, when uttering a bare sentence, unless she is lying (in which case she is not being co-operative in Gricean terms), she shares information that she considers or knows, to be true. Veridical commitment can be public, as in the bare sentence, or private and purely subjective as is the case with verbs of imagination, fiction, and personal taste-where commitment can be even knowingly contested. In these cased the subjective veridical stance replaces knowledge, and we talk about solipsistic commitment, as we will discuss soon.

On the other hand, when a speaker choses to modalize she indicates an epistemic or doxastic state that lacks commitment, i.e, she is taking a nonveridical stance. She is now uncertain about whether it is raining or not. This epistemic uncertainty is gradient: with may or might or an expression such as It is possible that it rains, raining is considered a mere possibility, and the commitment is trivial in the sense that the possibility is not excluded. But when a necessity modal is used, raining is considered very likely, and with the future modal it is to be expected. In this case, we have talked about bias: the linguistic anchor is biased towards $p$.

Bias is supported by strong evidence in favor of the proposition, but it does not mean that the speaker knows $p$ to true. Modals are anti-knowledge markers; a speaker choses to use an epistemic modal because they are not absolutely certain about the truth of $p$. Epistemic modal verbs are indicators that the speaker reasons with uncertainty and that she leaves open both options, $p$ and not $p$, open. Consider below some attested examples (from Lassiter 2016, cited in GM): ${ }^{2}$

a. This is a very early, very correct Mustang that has been in a private collection for a long time. . . . The speedo[meter] shows 38,000 miles and it must be 138,000, but I

\footnotetext{
${ }^{1}$ There are, of course, non-cooperative conversations such as advertising, propaganda, so-called bullshit (Frankfurt 2005), or types of political speech where truthfulness is not required. These cases deserve full consideration, but on a different occasion. The framework we develop here and in our more extensive prior work offers a number of tools that will be helpful for the analysis of non-cooperativity and deceptive language.

${ }^{2}$ See also Trnavac and Taboada 2012 for a corpus study that includes modal verbs as non nonveridicality markers.
} 
don't know for sure.

b. I don't know for sure, sweetie, but she must have been very depressed. A person doesn't do something like that lightly.

c. It must have been a Tuesday (but I don't know for sure), I can't remember.

d. I have an injected TB42 turbo and don't like the current setup. There is an extra injector located in the piping from the throttle body . . . Must be an old DTS diesel setup but I'm not certain. Why would they have added this extra injector?

Hence, despite the fact that must is a necessity modal, it still does not entail knowledge of, or commitment to, $p$ by the speaker. The use of a modal is always an indication that inference to $p$ contains gaps and uncertainty.

Consider also the following case, which has been discussed in the literature quite a lot. Direct visual perception contexts are famously cited as rejecting modalization:

(4) Context: $i$ is standing in front of the window and sees the rain.
a. \#It must be raining.
b. \#It may be raining.
c. \#It might be raining.

The modals are infelicitous here because if I see the rain, I know that it is raining, and knowledge is veridical; therefore modalization is prohibited because direct evidence is a reliable path to knowledge. Giannakidou and Mari (2016) note that modal statement statements can be continued by "but I am not entirely sure" (as first noted in Bertinetto 1979; Mari 2009, Giannakidou and Mari 2012b,2013):

He must/may be home, but I am not entirely sure.

Veridical assertions do not accept such continuation:

a. \#He is at home but I am not entirely sure.

b. \#I know he is at home but I am not entirely sure.

Clearly then, modal statements are incompatible with veridical commitment to $p$.

In our recent work, we have defined commitment based on veridicality as a scale, and we summarize the gist below. Veridical commitment is full commitment: the speaker knows $p$ or believes it to be true, she is in a veridical state and therefore fully committed to $p$. We will call this state of full commitment epistemic commitment, although as we said earlier it is a combination of knowledge and belief, broadly construed. The scale of epistemic commitment looks as follows; upper case MUST and MIGHT indicate the family of words which crosslinguistically correspond to the English modals:

(7) Scale of commitment (Giannakidou and Mari 2016, 2021):

$<p$, MUST $p$, MIGHT $p>$;

where $i$ is the speaker, $p$ conveys full commitment of $i$ to $p$; MUST $p$ conveys partial commitment of $i$ to $p$, and MIGHT $p$ conveys trivial commitment of $i$ to $p$.

The nonveridical stance, in other words, creates weaker commitment, one where the linguistic anchor reasons with uncertainty. In the nonveridical stance, the mental state allows both options $p$ and $\neg p$. In the case of possibility modals, there is no bias towards $p$, the options are, as we say, in nonveridical equilibrium, state or 'balanced uncertainty'.

Nonveridical equilibrium characterizes also questions: 
Did it rain yesterday?

(9) I wonder whether it rained yesterday.

The question indicates a state of uncertainty that is similar to that of modals of possibility: it might have rained yesterday and Did it rain yesterday? convey the same state or 'balanced uncertainty' in the sentence that the two possibilities (rain, not rain) are equal in terms of what the speaker believes or knows to be the case.

Finally, when we consider actual information conveyd, commitment entails the following:

$$
\begin{aligned}
& \text { Commitment and informativity: (Giannakidou and Mari 2016): } \\
& <p \gg \text { MUST } p \gg \text { MIGHT } p>\text {; where " } \gg " \text { means "informationally stronger than" } \\
& \text { Nonmodalized } p \text { (speaker knows } p, p \text { added to the common ground) } \gg \\
& \text { MUST } p \text { (speaker does not know } p \text {, but is biased toward } p \text { ) } \gg \\
& \text { POSSIBLY } p \text { (speaker does not know } p \text {, and there is nonveridical equilibrium) }
\end{aligned}
$$

Only the veridical, committed assertion of $p$ adds $p$ to the common ground as public knowledge. Introducing a modal creates an informationally weaker sentence. With a possibility modal, just as with a question, we simply don't know whether there is any evidence to support $p$. Bias toward $p$, in turn, is informationally stronger than nonveridical equilibrium but still does not make the audience think that $p$ is true- only that is is likely. In other words, only the bare sentence gives actual information about the world.

\section{The formation of commitment and the body of evidence}

In this section, we will ponder a little bit more on how commitment is formed. Is commitment based on what is true, or is it an evaluation of what is perceived or understood as true by a linguistic agent? Is commitment based on evidence alone? Or can it be influenced by endogenous factors and biases that can create purely solipsisitc beliefs, only partially or not-at-all based on reality? Dissecting the state of commitment is key to understanding the nature of veridicality judgement.

Truth is the foundation of logic, the study of linguistic meaning, and axiomatization in science. Aristotle gives a well-known definition of truth in his Metaphysics (1011b25): "To say of what is that it is not, or of what is not that it is, is false, while to say of what is that it is, and of what is not that it is not, is true." Very similar formulations can be found in Plato (Cratylus 385b2, Sophist 263b). The Aristotelian truth serves as the foundation for the main paradigm of truth-conditional semantics that we use in linguistic analysis, and Tarksi's correspondence theory of truth.

Truth, in the correspondence theory, consists in a direct relation of a sentence to reality: the sentence Snow is white is true if and only if the snow in the world is white. This well-motivated understanding is central to natural language semantics, and implies metaphysical realism that acknowledges objective truth. Objective truth correlates with fact but also with time: simple positive present and past sentences such as Ariadne arrived in Paris last night, Ariadne is eating breakfast right now, are true or false objectively, which means that the sentences, if true, denote facts of the world. Future sentences, on the other hand, such as Ariadne will go to Paris next week are objectively false at the time of utterance (since they have not happened yet), but could or must be true-depending on the strength of prediction - at a future time.

When I use a knowledge predicate I engage truth directly:

$$
\text { Mary knows that Ariadne read War and Peace. }
$$

The know predicate is characterized in the literature as factive (Kiparksi and Kiparki 1970): that Ariadne read War and Peace is fact. A fact is a true proposition, notice that the negative sentence 
Mary doesn't know that Ariadne read War and Peace still entails that Ariadne read War and Peace. The word know and its equivalents (upper case KNOW henceforth) is a propositional attitude predicate: it says that the subject of KNOW stands in the knowing relation to the fact that Ariadne read War and Peace. KNOW predicates in language are often characterized as presuppositional because they indeed require that the complement be a fact, therefore true.

Now, as we said earlier, when the speaker co-operatively utters the sentence:

Ariadne read War and Peace.

they are making a claim about what they consider or know to be true (based on what we just said in the previous section), i.e., they are in a veridical stance to the sentence, they are committed to it. How is the commitment formed? Speakers and hearers form judgments about the truth of statements based on what they know, expect, or believe (Giannakidou 1998, 1999, 2013; Harris and Potts 2010; de Marneffe et al. 2012; Mari et al. 2013 on perspectival generics; Mari 2009, 2015, 2016 , 2018, to appear). That such relativization is needed becomes visible when a modal expression is used; but it is intuitively cleat that every sentence is interpreted against prior knowledge or experience. Harris and Potts 2010 express this very clearly in their assertion that "all sentences are perspectival".

When speakers make assertions or ask questions or assess statements of others, they make veridicality judgments that are not ex nihilo, but rather based on their own body of information or perspective. The veridicality judgement is more complex than truth assignment: it depends on what speakers know or believe to be true, and on how they extract information from context (see especially Giannakidou 1998, 2013; Mari 2009; Giannakidou and Mari 2016; de Marneffe et al. 2012 confirm this complexity with corpus data). The basis for commitment can therefore not be just truth itself. When a speaker makes calls about truth, they use a body of information that we call the body of evidence, and the body of evidence determines the veridicality judgement.

The body of evidence contains two types of content. First, there is declarative informative content, namely what the speaker or subject of attitude knows to be true, believes to be true, remembers, or understands to be true- what kind of information they have, in other words. If commitment to truth is sincere, this type of content is evidential. Secondly, the body of evidence is rational, hence it contains logical deductive rules, as well as inductive, stereotypical generalizations that guide rational thought. For instance, if the speaker has heard that Ariadne read War and Peace from a reliable source, they will take this hearsay information to be true and convey it as true; but if they hear the same sentence uttered by a pathological liar, rationality should make the speaker reluctant to commit themselves to the sentence. Likewise, if I wake up in the morning and I see the streets being wet, I can truthfully report this by saying It rained last night, because it is rational to infer, by the wetness of the street, that it rained - and less rational to say, for example, that it snowed, or The neighbors left the water running again.

Reasoning with the future also allows us to see the effects of rationality. Consider:

John will be here at 5 .

In everyday life, we constantly evaluate whether the actual world follows stereotypical rules. What counts as normal or reasonable outcome depends on one's knowledge and experience, and human agents make use of expectations relying on knowledge and experience when they reason. Normalcy and reasonability manifest themselves in various forms in language ${ }^{3}$, for instance also when ignoring exceptions with generic statements: the generic statement Dogs bark precludes abnormal instances of dogs; see discussion in Mari et al. 2012.). Of course, actual outcomes do not always conform to what is expected under normalcy conditions, and the expectation of not conforming to

${ }^{3}$ See Dowty 1979. 
what it is "normal" determines often our uncertainty. But when we utter a sentence like (13), we rely on normalcy conditions and rationally about the future.

Hence linguistic agents form veridicality judgements based on information they have and general rules of inference, and chose accordingly to commit fully, partly or trivially to a proposition.

There is another type of content that is relevant and may interfere with the body of evidence. We will call this emotive content. This content is highly subjective and to a large extent private: it contains the set of desires and hopes of the linguistic agent, as well as their political, ideological, religious, or esthetic beliefs. This component is not so relevant to whether Ariadne read War and Peace, or to whether John will be here by $5 \mathrm{pm}$, and plays no role in the assertability veridicality condition in these inocuous cases. If I hate Russian writers, and I know that Ariadne read War and Peace but I wish she hadn't, I still utter Ariadne read War and Peace truthfully.

But the emotive component becomes relevant when the sentence contains so-called subjective predicates:

\section{War and Peace is a masterpiece. \\ Donald Trump is brave.}

These sentences express opinions. Opinions do not depend on evidence alone, and are highly dependent on the emotive component (which, needless to say, need not be rational). For instance, if I hate Russian writers, most likely I will not utter (14), and upon hearing it I will object with (16) below. Likewise, if I am a fun of Donald Trump I will take (15) to be true-even though my commitment to it maybe be based on a factual confusion of rudeness with bravery; as we said, the emotive component need not be rational. If I disapprove of Donald Trump, I will disagree (17):

War and Peace is not a masterpiece.

Donald Trump is not brave.

Here we have what has been called in the literature faultless disagreement (Lasesohn 2005). Two agents can be confronted with the same information or set of facts (body of evidence), but they can draw different conclusions based on their set of subjective assumptions about what counts as being a masterpiece and being brave. The disagreement is faultless because the evaluation now includes the emotive component, and is judged against that. Two speakers can commit to the one or another direction. Predicates of personal taste have this characteristic property, and are pervasive in language. Examples include tasty, fun, beautiful, scary, etc:

Fish is tasty.

That movie was scary.

That old house is beautiful.

People systematically disagree about the 'correct' application of these predicates when they express opinion. Opinion is distinct from knowledge, it is private, and based on both evidence and the emotive component. Disagreements may never be settled because they are not simply factual. It is not merely a matter of fact if $\mathrm{X}$ is a masterpiece or $\mathrm{X}$ is brave, but as Lasesohn puts it, it is a matter of opinion. Opinion alone, it must be emphasized, cannot form the basis of knowledge and validity because it is not factual but subjective. Two agents can have two differing opinions when confronted with the same set of facts, as we said. Opinions, therefore, cannot be true of false; you just have them, and they are consistent or inconsistent depending on whether they follow from the agent's internal assumptions of not. Blurring the distinction between knowledge (which is factual) and opinion (which is not) leads to un-cooperative argument which Plato would call sophistry and Frankfurt calls bullshit. 
Let us now introduce the puzzle of mood. This will allow us to see more workings of the subjective component and of its complex interaction with factuality and rationality, and add further distinctions about the evidential bases that ground knowledge and belief judgements.

\section{Knowledge and belief predicates: indicative and subjunctive}

Mood choice is a multidimensional phenomenon, as we illustrate in our recent book, involving interactions between syntax, semantics, and pragmatics; and raises a number of issues that are literally invisible if we pay attention only to English simply because Modern English lacks the morphological category of mood in embedded clauses. Despite this absence, terms such as "subjunctive" and "indicative" continue to be routinely used, e.g., in the discussion of English conditionals, often misleading us to think that we are dealing with a mood phenomenon. (We are not. Indicative and subjunctive conditionals are really about tense. ${ }^{4}$ )

Natural languages vary in the vocabulary, form, and grammatical categories that realize mood; yet in addressing the question of language and thought, most continental philosophy overlooks this striking variation and almost exclusively focuses on English. This focus affects negatively the set of data deemed relevant for analysis, and in effect diminishes, not to say dismisses, the role of linguistic diversity in revealing aspects of the logic needed in order to handle accurately and successfully the central questions of truth and knowledge. In our book, we explore the interaction between truth, knowledge, and veridicality judgement as they interact in the grammatical phenomenon of mood choice (subjunctive, indicative) in European languages. Our main illustrators are Standard Modern Greek and the Romance language family, with specific emphasis on Italian and French. Here, we will limit ourselves to the very basic variations in order to keep the data manageable.

Observe the basic contrast in French and Italian:

a. Marc sait que le printemps est/ *soit arrivé.

Marc knows that the spring be.IND.3sg/ be.SUBJ.3sg arrived.

Marc knows that spring has arrived.

b. Marc veut que le printemps soit/*est long.

Marc wants that the spring be.SUBJ.3sg/be.IND.3sg long.

Marc wants spring to be long.

c. Le printemps est/*soit arrivé.

The spring be.IND.3sg/be.SUBJ.3sg arrived.

The spring has arrived.
a. Marco sa che la primavera è/*sia arrivata
Marco knows that the spring be.IND.3sg/be.SUBJ.3sg arrived.
'Marc knows that spring has arrived.'
b. Marco vuole che la primavera sia/*è lunga.
Marco wants that the spring be.SUBJ.3sg/be.IND.3sg long.
'Marc wants spring to be long.'
c. La primavera è/*sia arrivata.
The spring be.IND.3sg/be.SUBJ.3sg arrived.
The spring has arrived.

The verb of knowledge savoir/sapere ('know') selects the indicative in both French and Italian

\footnotetext{
${ }^{4}$ A typical subjunctive conditional is a counterfactual 'If John had ask for help, he would have received it.' Indicative conditionals are about future and possibilities that can still become actual: 'If John asks for help, he will receive it.'
} 
(21-a)-(22-a), but the volitional verb vouloir/volere ('want') selects the subjunctive in both languages (21-b)-(22-b). The indicative is the default mood of unembedded sentences, as indicated in (21-c)-(22-c). This is a typical pattern in all European languages; and in the cases above, the mood morphemes are in complementary distribution, i.e., one mood excludes the other. ${ }^{5}$

Interestingly, in Greek, as well as French, verbs of belief (doxastic) pattern with knowledge in selecting the indicative. We illustrate with Greek:

$$
\text { O Pavlos kseri oti//*na efije i Roxani. }
$$

the Paul know.PRES.3sg that.oti.IND/pu.IND/*SUBJ left.3sg the Roxani. Paul knows that Roxanne left.
O Pavlos pistevi
oti//*na
efije i Roxani.
the Paul knowPRES.3sg that.IND/*SUBJ left.3sg the Roxani.
Paul knows that Roxanne left.

Nomizo (think), pistevo (believe) take indicative oti, complements, not subjunctive- even though the complement may be objectively false, as we will see soon. The same is true of French:
Je sais
que Marie est enceinte.
I know/Think.PRES.1sg that Mary is.SUBJ pregnant.
I know that Mary is pregnant.
Je crois
que Marie est
enceinte.
I believe/Think.PRES.1sg that Mary is.SUBJ pregnant.
I believe that Mary is pregnant.

It seems to be a robust generalization that in Greek and French epistemic and doxastic attitude verbs pattern on a par in selecting indicative. This is a problem for the traditional characterization of mood being dependent on realis versus irrealis (see discussion in Giorgi and Pianesi 1996), because clearly the complement of belief verbs is not realis.

The doxastic verbs are solipsistic, we argue: they rely on the private veridicality commitment of the attitude holder's doxastic space, ignoring what is in the common ground and lacking entirely factual commitments. Consider more closely the case below:

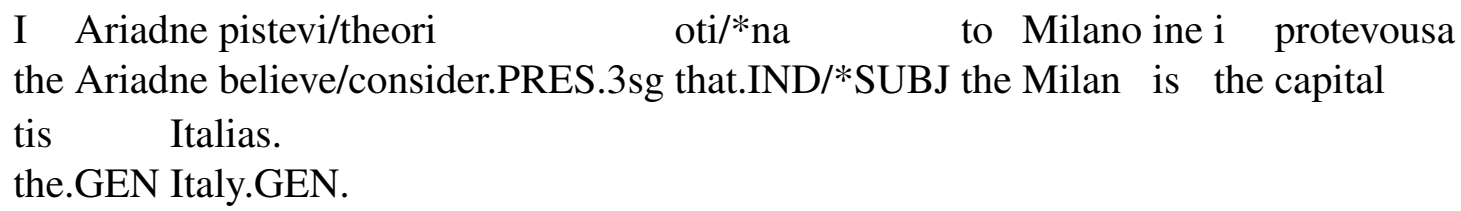

Ariadne believes that Milan is the capital of Italy./Ariadne considers Milan to be the capital of Italy.

That Milan is the capital of Italy is objectively false; however, the speaker can use this sentence to report Ariadne's contested belief, and the speaker would have to use the indicative mood, designated by the mood particle oti, which in Greek surfaces as a subordinator (equivalent to that). The Greek subjunctive particle $n a$ is, crucially excluded.

The fact that indicative and not subjunctive is used to convey this obviously false belief indicates that, despite what the speaker knows to be the case and what $i s$ objectively the case, when it comes to mood selection, grammar forces Ariadne to lay claim to the veridicality of her belief, and

\footnotetext{
${ }^{5}$ Though the indicative-subjunctive pattern has been most extensively described in Indo-European languages, it is by no means restricted to these. It appears in many of the world's languages, including Native American languages (see a recent article by Matthewson 2010 for Salish, and Wiltschko 2016). The contrast between subjunctive and indicative also correlates with evidentiality, especially in languages that have only one indirect evidential morpheme (Murray 2016; Smirnova 2013).
} 
forces the speaker to follow suit, regardless of relation to actual truth. ${ }^{6}$ The selection of indicative with belief and doxastic verbs is observed not just in Greek and French, but seems to be the rule in most Romance languages (with the exception of Italian and some varieties of Portuguese and Spanish that we will present next).

Indicative extends further to other fictional classes such as attitudes of dream, imagination, and deception:
I Ariadnie onireftike oti/*na
to Milano ine i protevousa tis the Ariadne dreamt.3sg that.IND/*SUBJ the Milan is the capital the.GEN Italias.

Italy.GEN.

Ariadne dreamed that Milan is the capital of Italy.
I Ariadne ksejelastike/ fantastike oti/*na
to Milano ine $\mathrm{i}$
the Ariadne was.deceived.3sg/ imagined.3sg that.IND/*SUBJ the Milan is the protevousa tis Italias.
capital the.GEN Italy.GEN.
Ariadne was deceived/imagined that Milan is the capital of Italy.

The use of indicative in fictional contexts and with doxastic verbs to convey objectively false beliefs forces us to distinguish truth — as a matter of fact—-from the subjective construct of veridicality judgment, where truth is assessed relative to the internal cognitive states of linguistic agents. We will call this solipsistic belief. ${ }^{7}$

Italian and Portuguese, on the other hand, allow us to see a different, non-solipsistic construal of belief with subjunctive. Consider Portuguese first:
Acredito que a Maria está doente.
believe-1sg that the Maria is-IND-3sg ill.
I believe that Maria is ill.
Acredito que a Maria esteja doente.
believe.1sg that the Maria is.SUBJ.3sg ill.
I believe that Maria might be ill.

Marques says that the selection of one or another mood is related to the "degree of belief" being expressed: the indicative signals a high degree of belief, and the subjunctive a lower degree, reflected in English above with the use of the modal might. According to Marques, "the concept of veridicality accounts for this case of mood variation. With the indicative, the inference follows that the relevant proposition is true (according to the subject of the main clause), contrary to what happens if the subjunctive is selected." (Marques 2010, p. 145).

Italian is another well-known exception to the generalization that epistemic select indicative (see for the foundational discussion Giorgi and Pianesi 1996).
Credo/Penso
che Maria sia
incinta.
Believe/Think.PRES.1sg that Mary is.SUBJ.3sg pregnant.
I believe that Mary might be pregnant.

\footnotetext{
${ }^{6}$ See also Morency and de Saussure (2008), who argue that whether a speaker commits to a content embedded as a report is entirely pragmatic.

${ }^{7}$ The need to appeal to "relative truth" for mood choice has long been acknowledged since McCawley's (1981) and Farkas' (1985) work in the eighties and early nineties. Building on these pioneering works, Giannakidou (1998, 1999) used the expressions relativized veridicality.
} 
Credo/Penso che Maria è incinta.

Believe/Think.PRES.1sg that Mary is.IND.3sg pregnant.

I believe that Mary is pregnant.

The Italian doxastics are therefore mood flexible. Again, notice that the effect in English is produced with the use of the modal verbs might.

The use of the subjunctive and the modal can be taken to indicate some form of weakness in the doxastic commitment, e.g., creating a nonveridical doxastic space with both options of $p$ and its negation (see Marques 2010 for Portuguese just mentioned). But verbs of certainty and conviction also select subjunctive, and when one is certain or convinced, one is doxastically committed to $p$, i.e., there are no $\neg p$ possibilities allowed in the subject's doxastic state with we call Dox.

(34) Sono sicura che Maria sia/è incinta.

Am certain.PRES.1sg that Mary be.SUBJ/IND.3sg pregnant.

I am certain that Mary is pregnant.

(35) Sono convinta che Maria sia/è incinta.

Am convinced.PRES.1sg that Mary be.SUBJ/IND.3sg pregnant.

I am convinced that Mary is pregnant.

In Giannakidou and Mari 2021, we argue that the contrast between the indicative and modal/subjunctive shows that commitment can be solipsistic and purely subjective (indicative)—or suppositional and conjectural (Mari 2016) in which case is contrasted with not-knowing. We take up that discussion in the next sections.

\section{Ways to relate to the outer world: fictional predicates}

Flexible mood choice is a powerful device to identify different interpretations of epistemic, doxastic, and fictional attitudes, unveiling two different manners by which speakers relate to the actual world. Fictional predicates are particularly revealing of these two ways of apprehending reality.

As mentioned earlier, fictional attitudes like 'dream', 'imagine' are cross-linguistically described as selecting indicative (e.g. Giorgi and Pianesi, 1996; Giannakidou, 1999). They convey subjective veridicality: the mental space of the attitude holder is homogeneous and contains only the $p$-possibility. The semantics for fictional attitudes thus mimics what is known in philosophical discussion as Hintikkean belief, i.e, the belief that conveys commitment to $p$.

Mari (2016) notes that fictional predicates can also license the subjunctive in Italian (see (36)).

$$
\begin{aligned}
& \text { Immagino che Maria sia incinta. } \\
& \text { Imagine. } 1 \mathrm{sg} \text { that Mary be.SUBJ.3sg pregnant. } \\
& \text { I imagine that Mary is pregnant. } \\
& \text { Immagino che Maria è. } \\
& \text { Imagine. } 1 \mathrm{sg} \text { that Mary be.IND.3sg pregnant. } \\
& \text { I imagine that Mary is pregnant. }
\end{aligned}
$$

There is a difference in the interpretation triggered by the use of the two moods. When the indicative is chosen, immaginare describes a solipsistic space of imagination. When the subjunctive is chosen, immaginare conveys a conjecture. The same distinction exists in English.

Mary is silent, open eyes dreaming.

Mary is imagining that she is a top model.

I imagine that you were late today at school, given the traffic. 
(38) reports a pure state of imagination of Mary. (39), on the other hand, reports a conjecture, $p$ can be either true or false in the context of utterance. Only in the latter case is knowledge at stake. In the conjectural use the speaker does not know, but estimates that her interlocutor was late at school. In Italian, this difference is made visible by mood. The conjectural use is triggered by the subjunctive, the solipsistic use, by the indicative. In a context where Mary is explaining to Susan why John was silent and sad the solipsistic use surfaces:

$$
\begin{aligned}
& \text { Immaginava che andava in Italia. } \\
& \text { Imagine.PAST.IMP that go.IND.3sg in Italy. } \\
& \text { He was imagining that he was going to Italy. }
\end{aligned}
$$

(41) is another example illustrating that subjunctive triggers a conjectural interpretation of immaginare.

$$
\begin{aligned}
& \text { Immagino che tu sia arrivato in ritardo questa mattina a scuola. } \\
& \text { Imagine.IND.1sg that you be.SUBJ.2sg arrived in late this morning to school. }
\end{aligned}
$$

I imagine you must arrived late this morning at school.

Intuitively, here, an 'I do not know' component is active, reflected in English with must. (Likewise, in Greek; the use of a modal in lieu of subjunctive appears to be a general crosslinguistic strategy.). The sentence states that, the speaker does not know whether $p$ is true, but she is reporting that in possibilities that are compatible with what she knows and which comply also with her imagination, her interlocutor has arrived late at school.

With the solipsistic-iimagine, the attitudes holder is committed to a reality that is not believed to be actual. With the conjectural-imagine, the attitude holder proposes a conjecture about how the actual reality can be like. Solipsistic-imagine uses emotive or endogenous evidence, that it is to say, a representation that has an entirely private, inner source. Conjectural imagination, on the other hand, uses exogenous evidence, that it is to say evidence rooted in the actual world. We come back to this distinction extensively in Section 7.

\section{Solipsistic and suppositional belief}

In Giannakidou and Mari (2021) we argue that engagement or not with knowledge allows us to distinguish two kinds of belief. The indicative belief is solipsistic and does not engage knowledge, but is based purely on a veridical state of mind. This solipsistic state of mind can be grounded on emotive evidence, and we can think of the solipsistic belief as a credence (to use a term from Mari 2016). Very typically and expectedly, then, indicative (which has a very restricted use with belief) is found in religious discourse and prayers.

(42) Apostolato della sofferenza (Apostolate of suffering): (attested examples reported in Mari and Portner 2019)

a. Credo che il dolore distacca,

Believe.PRES.IND.1SG that the pain detach.PRES.IND.3SG,

disillude, $\quad$ purifica, migliora, anzi

disilluse.PRES.IND.3SG, purify.PRES.IND.3SG, improve.PRES.IND.3SG, even

conduce l'anima alla più alta perfezione.

guide.PRES.IND.3SG the soul to the most high perfection.

'I believe that pain detaches, reveals truth, purifies, improves, and indeed guides the soul to the highest perfection.' 
b. Credo che Dio è vicino a quelli che

Believe.PRES.IND.1SG that God be.PRES.IND.3SG close to those who

soffrono per Lui.

suffer.PRES.IND.3PL for Him.

'I believe that God is close to those who suffer for Him.'

Credence can be based on rational arguments, but it is mostly based on opinions, emotive/bouletic reasons, and is often irrational. In the credence solipsistic interpretation, the knowledge component and the body of evidence are not relevant. Solipsistic belief can thus turn into dogma in all possible cases where truth does not matter but credence does.

When belief engages with knowledge Italian chooses subjunctive and English a modal.

Credo che Maria sia incinta.

Believe.1sg that Mary is pregnant.

I believe that Mary must/might be pregnant.

Belief now contains an 'I do not know' component and is a supposition or conjecture. While in every language the conjectural use of belief is present, only some languages (called $\pi$-type languages by Mari 2016) are sensitive to it when it comes to mood choice.

These two types of belief-solipsistic belief or credence, and conjectural belief-are informative of two different manners whereby speakers and epistemic agents engage with the reality. With solipsistic belief, they 'project' a reality. With the conjectural use, they 'reconstruct' the reality based on external clues. The communicative goals of solipsistic and conjectural belief are thus not the same: with the solipsistic use the speaker wants to make the credence of the attitude holder known; with the conjectural belief the attitude holder proposes a view of what the outer world can be like, and in particular proposes that $p$ might be true (Mari 2017).

These two types of beliefs are grounded in different types of evidence to which we now turn.

\section{Direction of fit and evidential underpinnings}

It is useful at this juncture to consider the 'direction of fit'. Firstly used for speech acts by Searle (1975), this notion can be extended to attitudes and the types of evidence in which attitudes are rooted. According to common wisdom, belief follows from the world, whereas desire, for instance, projects a world. We have unveiled here two different types of beliefs: belief that follows from the world (the conjectural belief) — engages with objective reality_, and belief that projects a world (the solipsistic belief).

There is inner to outer direction of fit with solipsistic attitudes: the agents represents the reality based on an internally born representation. They can consider this inner representation as a faithful representation of the real world, or just withdraw their commitment about whether their own representation can be taken to be a faithful one for the outer world.

There is an outer to inner direction of fit with conjectural attitudes: the agents form a representation of the reality based on external clues, and try to form a faithful representation of the outer world. These two movements (inner to outer and outer to inner) have important evidential underpinnings again when we consider flexible mood choice in Italian (described in Mari's earlier work that we rely on here):

A group of friends is looking for a restaurant. One of them suggests:

a. Andiamo lì, credo che è buono.

Go.IMP.1pl there, believe.IND.1sg be.IND.3sg good.

Let's go there ! I believe it is good! 

b. Andiamo lì, credo che sia buono.
Go.IMP.1pl there, believe.IND.1sg be.SUBJ.3sg good.
Let's go there ! I believe it will be good!

Notice the use of the epistemic future modal in English. Likewise, in Greek, the future particle produces the same effect:

Pame! Nomizo oti to estiatorio tha ine kalo!
Go.IMP.1pl there, believe.IND.1sg that/IND the restaurant FUT be.3sg good.
Let's go there ! I believe the restaurant will be good!

The future has a strong epistemic component (Mari, 2009; Giannakidou 2012, Giannakidou and Mari 2012, 2013, 2018a; Mari 2015, 2018). Well known cases in English are discussed in Palmer 1986, e.g. That will be the postman upon hearing a knock on the door, and Oil will float on water as a general rule with no temporal meaning since it is a definitional generic statement. We see in the Greek example that despite the use of the indicative subordinator, the future particle enables conjectural belief. Hence, we re-iterate that the transition from one type of belief to the other does not rely exclusively on mood but on modality expressions more broadly, as evidenced also by English. The absence of the mood category in English complements, therefore, is not deficiency, as point to which we will return.

By choosing the indicative the speaker reveals her own credence or preference for a particular restaurant, that relies on some internal perception (she has already eaten at that restaurant, she likes how it looks like, ...). The evaluation is subjective in a proper way, it is based on some subjective experience. This type of subjective judgment is un-commensurable with the one that could be expressed by other speakers and relies on their endogenous state. Emotive material is always endogenous as we noted above in relation with the solipsistic fictional interpretation of 'imagine' predicates. Endogenous material can also be rational. However, as we said earlier and discuss further below, it is never sufficient - by its very inner nature - to form a reliable picture of the reality, hence the unresolved situation of 'faultless disagreement'. 8

In choosing modalization, on the other hand, the speaker signals that she is engaging with knowledge, relying on some external or exogenous evidence: in (44-b) and (46) for instance, she is signaling that she has heard or read about the restaurant, and that there are 'objective' criteria for judging restaurants (pretty much like there are objective standards to judge a wine (see Mari, 2016, 2017)). Exogenous evidence is a body of knowledge that includes 'facts' (what it is known, seen, heard etc). These facts are 'objective' or at least 'shareable'. $p$ can be 'known' relatively to this body of knowledge and, relatively to this type of evidence, the evaluations of the participants are commensurable with each other (see also discussion in Mari and Portner 2019).

We thus obtain the following picture. With attitudes that engage with endogenous evidencesuch as solipsistic belief and solipsistic fictional attitudes-, the epistemic agent is in a veridical state. Endogenous evidence is never partial and thus it creates a homogenous mental state that excludes the negation of the proposition. As for belief, we call this veridical mental state, doxastic.

With conjectural belief and conjectural fictional predicates, the epistemic agents acknowledge 'lack of full knowledge'. The evidential basis of conjectural beliefs are facts, which are verifiable by other epistemic agents. These facts are the exogenous evidence. However, the very use of the attitude reveals that exogenous evidence is never total (see Giannakidou and Mari 2016).

\footnotetext{
${ }^{8}$ The endogenous material cannot be 'evidence', strictly speaking, since evidence always makes reference to what is the case, i.e., it always makes reference to the world. Hence all purely inner motivations for belief such as religious beliefs cannot be evidential. Political beliefs can partly be, since they are motivated by what is the case in the world, but the emotive component strongly affects them in this case, and this is, as we said, purely endogenous. It would be fascinating to study the relation between religious and political beliefs in the framework we have developed here- a task that we will have to leave for a future ocassion, however.
} 
Exogenous evidence is always partial when it comes to epistemic attitudes other than 'know'.

\section{Conclusion: evidence, reliability, and veridicality vs. truth}

As we conclude our discussion, it is important to emphasize that the source of evidence also determines different degrees of reliability and commitment to the 'objective truthfulness' of $p$. Endogenous 'evidence', in spite of the fact that it enhances a veridical mental state, is not informative enough to allow one to draw a reliable picture of the reality. Exogenous evidence, even if partial, is more reliable, by the very fact of relying on external or factual clues. We thus obtain a picture where it is not only the veridical-nonveridical distinction that determines the level of commitment to the objective truthfulness of $p$, but also the source of the evidence.

With solipsistic belief or credence, the speaker is fully committed to $p$ based on doxa (belief). With conjectural belief, the speaker is at least partially committed to $p$ based on facts (partial public commitment). The latter commitment, albeit partial, is more reliable than the one based on endogenous assumptions: e.g., imagination or dreaming are veridical commitments, but far from being reliable. Credence (and a fortiori dogma) is of the same type, it is veridical but unreliable.

KNOW is the only attitude that reveals exogenous and total evidence on behalf of the attitude holder. It thus conveys full public commitment. Let us summarize this in the following table, which is an elaboration on Mari (2017).

\begin{tabular}{|c|c|c|c|}
\hline Type of attitude & Solipsistic Belief & Conjectural Belief & Knowledge \\
\hline \hline Evidence Type & Endogenous and Total & Exogenous and Partial & Exogenous and Total \\
\hline Reliability & Non reliable & Partially reliable & Totally Reliable \\
\hline Commitment & Full private commitment & Partial public commitment & Total public Commitment \\
\hline
\end{tabular}

Table 1: Types of beliefs and types of evidence

As we see, attitudes are rooted in evidence and the evidence determines not only their status with respect to (non)-veridicality, but also their status with respect to commitment, establishing a distinction between private and public commitment, which was absent in the initial characterization of commitment in (10). When evidence is exogenous, it is shareable and the attitude enters the realm of knowledge. Knowledge can be total ('know') or partial ('conjectural belief'). Exogenous evidence engages with public commitments, whereas endogenous assumptions do not allow engaging publicly (again, recall that all languages have a distinction between solipsistic and conjectural belief, just it is not made visible by mood and modality).

In our view, commitments (public or private) are ground in evidence. When speakers make assertions or ask questions or assess statements of others, they make veridicality judgments that are not ex nihilo, but rather based on their own evidential perspective. We offered concrete suggestions of how to model the structure of this perspective- which crucially, in our view, remains independent of the specific language tools used. As we showed, Greek and English do not mark the conjectural belief via the subjunctive, but resort to the use of a modal verb or a modal particle (the Greek future particle); and the absence of the specific grammatical category of subjunctive in English complement clauses does not entail that the semantic category of conjectural belief does not exist in this language. We have thus shown language to be resilient and not confining, contrary to what would be expected by the linguistic relativity hypothesis.

Finally, notice that at no point did we talk about relative truth. Rather, it is the veridicality judgement that is relative. Truth is objective and independent of the veridicality forming factors, i.e, the exogenous body of evidence and endogenous, privately sourced emotive assumptions. 
Truth, therefore, cannot be relativized. What is relativized is an individual's assessment of truth, which relies on subjective veridicality states, as we explained. Truth, in other words, is indeed a matter of fact, while commitment is a matter of subjective veridicality. Caution is therefore advised in using common expressions such as "my truth" and "your truth": they can only be understood as shorthands for an agent's veridicality judgement or perspective on truth, not as referencing truth itself. Subjective veridicality is an inner to outer direction of fit from language to world, while truth (partial or total) reflects an outer to inner direction of fit from world to language.

\section{References}

Dowty, D. (1979). Word Meaning and Montague Grammar. Dordrech: Kluwer.

Farkas, D. (1985). Intensional Descriptions and the Romance Subjunctive. New York: Garland.

Frankfurt, Harry G. 1986. On Bullshit. Raritan Quarterly Review. 6 (2): 81?100.

Giannakidou, A. (2013). Inquisitive assertions and nonveridicality. In Maria Aloni, Michael Franke, F. Roelofsen (eds.), The dynamic, inquisitive, and visionary life of $\phi$ A festschrift for Jeroen Groenendijk, Martin Stokhof and Frank Veltman, University of Amsterdam, 115-126.

Giannakidou, A. (1999). Affective dependencies. Linguistics and Philosophy 22, 367-421.

Giannakidou, A. (1998). Polarity Sensitivity as (Non)veridical Dependency. John Benjamins, Amsterdam.

Giannakidou, A. and Mari, A. (2021). Truth and Veridicality in Grammar and Thought. Mood, Modality and Propositional Attitudes. The University of Chicago Press.

Giannakidou, A. and Mari, A. (2018a). A unified analysis of the future as epistemic modality: the view from Greek and Italian. Natural Language and Linguistic theory 36(1), 85-129.

Giannakidou, A. and Mari, A. (2018b). The semantic roots of positive polarity: Epistemic modal verbs and adverbs. Linguistics and Philosophy, 461-487.

Giannakidou, A. and Mari A. (2016). Epistemic future and epistemic MUST: nonveridicality, evidence, and partial knowledge. In Blaszack, J. A. Giannakidou, D. Klimek-Jankowska, K. Mygdalski (eds.) Mood, Aspect and Modality: What is a linguistic Category?, University of Chicago Press.

Giannakidou, A. and Mari, A. (2013). A two dimensional analysis of the future: modal adverbs and speaker's bias. Proceedings of the Amsterdam Colloquium 2013, 115-122.

Giannakidou, A. and Mari, A. (2012). The future of Greek and Italian: An epistemic analysis. Proceedings of Sinn und Bedeutung 17: 255-270. http://semanticsarchive.net/Archive/Dk3NGEwY/Giannakidou

Giorgi, A. and Pianesi, F. (1996). Tense and Aspect. From Semantics to Morphosyntax. Oxford: OUP.

Kiparsky, P. and Kiparsky, C. (1968). Fact. Linguistics Club, Indiana University.

Lasersohn, P. (2005). Context dependence, disagreement, and predicates of personal taste. Linguistics and Philosophy 28: 643-686.

Lassiter, D. (2016). Must, knowledge, and (in) directness. Natural Language Semantics 24(2), 117-163.

Mari, A. (2017). Belief and assertion. Evidence from mood shift. Workshop Questioning Speech Acts. Kostanz, September 14-16.

Mari, A. (2016). Assertability conditions of epistemic (and fictional) attitudes and mood variation. Proceedings of SALT 26, 61-81.

Mari, A. (2015). French future: Exploring the future ratification hypothesis. Journal of French Language Studies 26(3): 353-378.

Mari, A. (2009). Disambiguating the Italian Future. Proceedings of the Generative Lexicon 2009, Pisa, pp. 209-216. 
Mari, A., Beyssade, C. and Del Prete, F. (2013). Genericity. Oxford: Oxford University Press.

Mari, A. and Portner, P. (2019). Mood variation with belief predicates: Modal comparison in semantics and the common ground. Ms. Institut Jean Nicod Paris and Georgetown University.

de Marneffe, M., C. Manning, and C. Potts. (2012). Did it happen? The pragmatic complexity of the veridicality judgement. Computational Linguistics 38, 300-333.

Marques, R. (2010). Modality, context change potential and mood selection in European Portuguese. In Becker, M., and Remberger, E. (eds.) Modality and Mood in Romance: Modal interpretation, mood selection, and mood alternation, La Linguistische Arbeiten 533, Niemeyer/de Gruyter, 133-161.

Matthewson, L. (2010). Cross-linguistic variation in modality systems: The role of mood. Semantics and Pragmatics 3.9, 1-74.

McCawley, J. D. (1981). The syntax and semantics of English relative clauses. Lingua 53(2-3), 99-149.

Morency, P. Oswald, S. and de Saussure, L. (2008). Explicitness, implicitness and commitment attribution: A cognitive pragmatic approach. Belgian journal of linguistics, 22(1): 197-219.

Murray, SE. (2016). The Semantics of Evidentials. Oxford University Press.

Palmer, F. R. (2001). Mood and modality. Cambridge University Press.

Fowler, H. N., 1926, Plato: Cratylus, Parmenides, Greater Hippias, Lesser Hippias, Loeb Classical Library, Cambridge Mass.: Harvard University Press.

Smirnova. A. (2013). Evidentiality in Bulgarian: temporality, epistemic modality, and information source. Journal of Semantics 30 (4), 479-532.

Trnavac, Radoslava, and Maite Taboada. 2012. The contribution of nonveridical rhetorical relations to evaluation in discourse. In Language Sciences 34: 301-318.

Rizzi, L. (1997). The fine structure of the left periphery. In Elements of grammar, Springer, Dordrecht, 281-337.

Wiltschko, M. 2016. The essence of a category. Lessons from the subjunctives. J. Blaszak, A. Giannakidou, Dorota Klimek and Krysztof Migdalski (eds.) Mood, Aspect, Modality revisited. New answers to old questions. University of Chicago Press. 218-254. 